\title{
Sea Surface Temperature Variability at the Scripps Institution of Oceanography Pier*
}

\author{
DAVID M. CHECKLEY JR. AND MARTIN LiNDEGREN ${ }^{+}$ \\ Scripps Institution of Oceanography, University of California, San Diego, La Jolla, California
}

(Manuscript received 29 October 2013, in final form 21 July 2014)

\begin{abstract}
Sea surface temperature (SST) has been measured from near the end of the Scripps Institution of Oceanography (SIO) pier daily since 1916. It is one of the world's longest instrumental time series of SST. It is widely used in studies of climate and marine ecosystems and in fisheries management. The authors hypothesized that a discontinuity exists in 1988, when the old pier was replaced with the present pier. A regression of

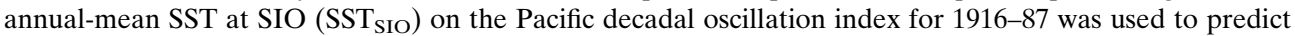

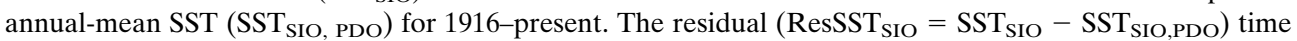
series shows a positive discontinuity in 1988 , when the present SIO pier was first used to measure SST $_{\text {SIO }}$. No discontinuity in 1988 was observed for ResSST at 12 other shore stations or in nearby waters. Use of the first principal component of other shore station time series of annual-mean SST as the predictor yields similar results. $\mathrm{SST}_{\text {SIO }}$ measured over 3 days shows a diel cycle and short-term variability consistent with rip current transport of warm surf-zone water to the end of the SIO pier. This study hypothesizes that rip current transport increased with the change from the old to the present pier and contributed to the observed discontinuity in SIO pier SST. The authors estimate an artifact of about $+0.45^{\circ} \mathrm{C}$ due to both rapid (1988 pier change) and gradual processes. Adjusting the SIO pier SST time series for this artifact reduces the long-term trend from $+1.1^{\circ}$ to $+0.6^{\circ} \mathrm{C}$ century ${ }^{-1}$, consistent with the global rate of change of SST over the past century.
\end{abstract}

\section{Introduction}

SST has been measured daily from the Scripps Institution of Oceanography (SIO) pier (La Jolla, California; $32^{\circ} 52.0^{\prime} \mathrm{N}, 117^{\circ} 15.5^{\prime} \mathrm{W}$ ) since 22 August 1916 (Fig. 1a). It is widely used in studies of ocean climate and marine ecosystems (Tegner et al. 1996; Gargett 1997; Mantua et al. 1997; Schwing and Mendelssohn 1997; McGowan et al. 1998; Dayton et al. 1999; Hare and Mantua 2000; Hobday and Tegner 2002; Lavaniegos and Ohman 2003; Hsieh et al. 2005; Breaker 2007; Breaker

\footnotetext{
* Supplemental information related to this paper is available at the Journals Online website: http://dx.doi.org/10.1175/JPO-D-130237.s1.

${ }^{+}$Current affiliation: Centre for Ocean Life, National Institute of Aquatic Resources, Technical University of Denmark, Charlottenlund, Denmark.

Corresponding author address: David M. Checkley, Jr., Scripps Institution of Oceanography, University of California, San Diego, 9500 Gilman Drive, La Jolla, CA 92093-0218.

E-mail: dcheckley@ucsd.edu
}

and Flora 2009; Kim et al. 2009; Mackas and Beaugrand 2010; Parnell et al. 2010; Hatch 2012; Sugihara et al. 2012; Deyle et al. 2013; Hatch et al. 2013; Jacobson and McClatchie 2013; Lindegren et al. 2013; Miller and McGowan 2013) and fisheries management (Jacobson and MacCall 1995; McClatchie et al. 2010; Lindegren and

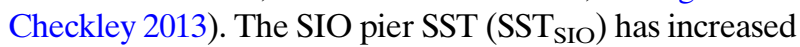
more rapidly $\left(+1.1^{\circ} \mathrm{C}\right.$ century $\left.{ }^{-1}\right)$ than global SST (+ $0.7^{\circ} \mathrm{C}$ century $\left.{ }^{-1}\right)$, indicating faster coastal than oceanic warming (Smith et al. 2008; Kadir et al. 2013). In 1988, the SIO pier, hereinafter termed the old pier ( $305 \mathrm{~m}$ long), was replaced with the present pier ( $322 \mathrm{~m}$ long). We hypothesized that the change in measurement of $\mathrm{SST}_{\mathrm{SIO}}$ from the old to the present SIO pier caused a discontinuity in the time series of annual-mean $\mathrm{SST}_{\mathrm{SIO}}$.

A standard protocol to measure SIO pier SST has been used since 1916. A weighted bucket is lowered through an opening in the pier by means of a hand winch and wire, filled, and raised to the pier deck. Temperature is measured immediately to $0.1^{\circ} \mathrm{C}$. The change from mercury to digital (thermistor) thermometers occurred gradually between 2008 and 2010 (M. Carter, SIO, 2013, personal communication). The sampling location on the 


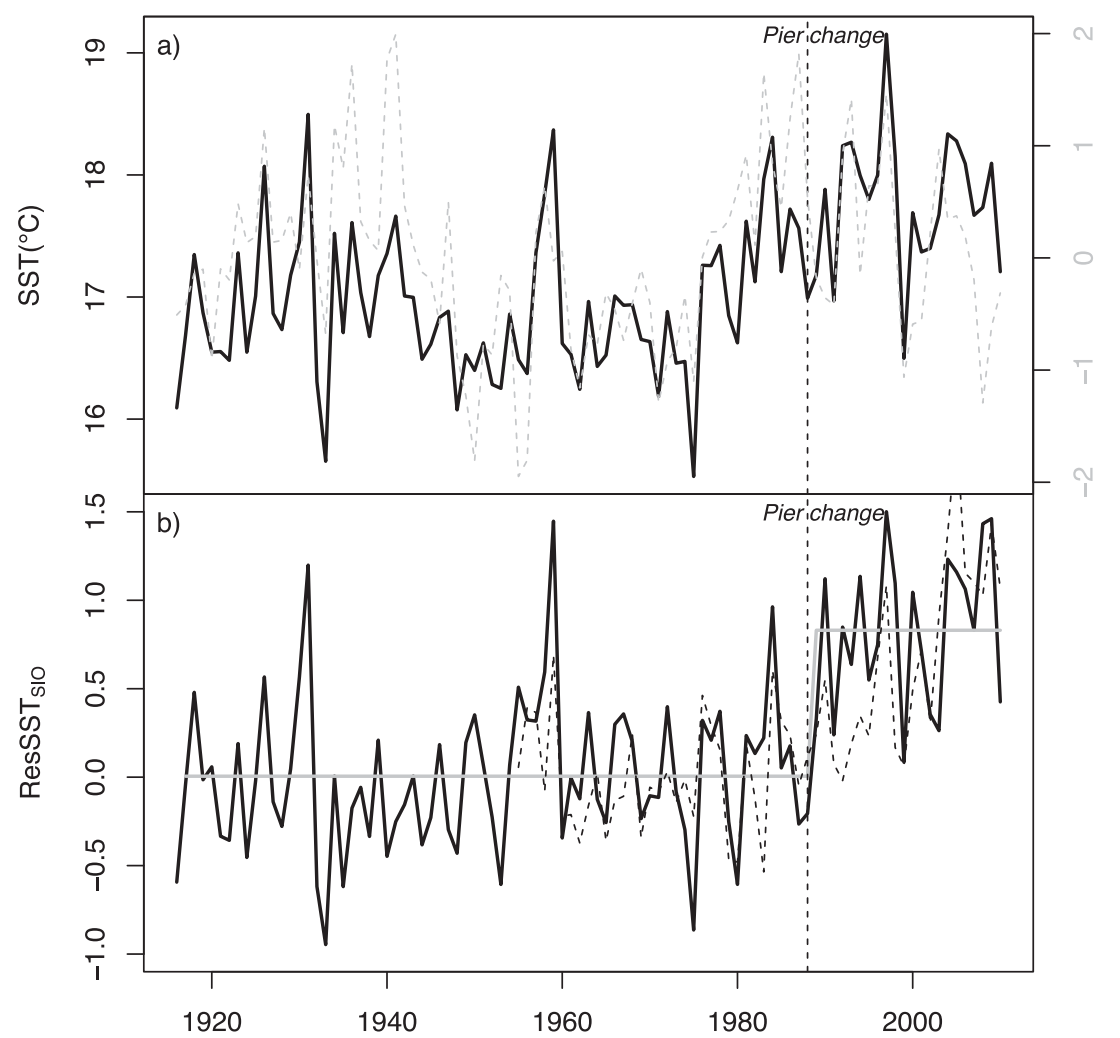

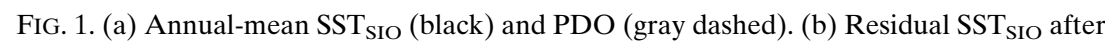

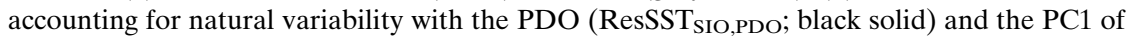

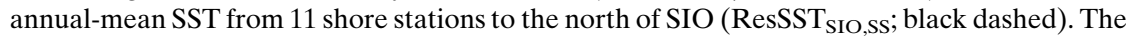

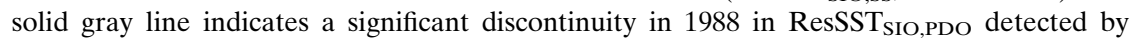
STARS, coinciding with the pier change.

present pier is $\sim 4 \mathrm{~m}$ seaward of that on the old pier. The time of sampling has varied between 0800 and $1700 \mathrm{~h}$ local time (LT) (SIO Shore Stations program; www. shorestation.ucsd.edu).

To test our hypothesis of a discontinuity in 1988 in the time series of annual-mean $\mathrm{SST}_{\mathrm{SIO}}$, we first account for large-scale natural variability and then apply two types of tests for discontinuity. We account for long-term natural variability by predicting annual-mean $\mathrm{SST}_{\mathrm{SIO}}$ using regressions of observed annual-mean $\mathrm{SST}_{\mathrm{SIO}}$ on two predictors: the Pacific decadal oscillation (PDO) (Mantua et al. 1997) and the first principal component (PC1) of SST time series for shore stations to the north of the SIO pier. We then use two types of tests for discontinuity in the time series of residuals between predicted and observed values of annual-mean $\mathrm{SST}_{\mathrm{SIO}}$. This allows for four tests (two time series and two test types) of our hypothesis. We then present and analyze a 3-day time series of SST $_{\mathrm{SIO}}$ using a new instrument. After presenting our results, we discuss rip current transport of warm surf-zone water as a possible cause of the observed discontinuity and implications of our study.

\section{Materials and methods}

Temperature data are from the SIO Shore Stations program, covering the entire U.S. West Coast (www. shorestation.ucsd.edu), and, for waters off Southern California, from the California Cooperative Oceanic Fisheries Investigations (CalCOFI) program (http:// calcofi.org/data.html) and the extended reconstructed sea surface temperature (ERSST.v3b) gridded reanalysis of global SST (ftp://ftp.ncdc.noaa.gov/pub/data/ $\mathrm{cmb} / \mathrm{ersst} /$ ) (Smith et al. 2008). Large-scale variability in SST $_{\text {SIO }}$ may mask the smaller hypothesized variability associated with the change in piers. For example, significant discontinuities in the daily SST time series at SIO and Pacific Grove in 1977 and 1989 have been identified (Breaker 2007). We accounted for natural large-scale variability by standardizing each annualmean SST time series using an underlying large-scale reference (predictor) variable. We tested five variables (Table 1). Selection of the variable with greatest explanatory power was objective. The PDO, the first principal component of the time series of detrended 
TABLE 1. Climate covariates used in model fitting.

\begin{tabular}{cll}
\hline \hline Abbreviation & \multicolumn{1}{c}{ Variable } & \multicolumn{1}{c}{ Source } \\
\hline PDO & Pacific decadal oscillation & $\mathrm{http}: / /$ jisao.washington.edu/pdo/PDO.latest \\
MEI & Multivariate ENSO index & $\mathrm{http} / / \mathrm{www}$.esrl.noaa.gov/psd/data/correlation/mei.data \\
NPGO & North Pacific Gyre Oscillation & $\mathrm{http}: / / \mathrm{www} .03 \mathrm{~d}$. .org/npgo/ \\
SOI & Southern Oscillation index & $\mathrm{http} / / \mathrm{www}$. esrl.noaa.gov/psd/data/correlation/soi.data \\
NOI & Northern Oscillation index & $\mathrm{http} / / \mathrm{www}$.esrl.noaa.gov/psd/data/correlation/noi.data \\
\hline
\end{tabular}

anomalies of SST poleward of $20^{\circ} \mathrm{N}$ in the North Pacific (Mantua et al. 1997), explained most variability in annual-mean $\mathrm{SST}_{\text {SIO }}$ (Table 2). Four other indexes [i.e., the multivariate ENSO index (MEI), North Pacific Gyre Oscillation (NPGO), Southern Oscillation index (SOI), and Northern Oscillation index (NOI)] did not explain significantly more variability in annual-mean $\mathrm{SST}_{\mathrm{SIO}}$ and thus were not further considered (Tables 1,2). Annualmean SST from ERSST.v3b for nine data blocks $\left(31^{\circ}-37^{\circ} \mathrm{N}\right.$, east of $123^{\circ} \mathrm{W}$ ) explained a relatively small amount of variability in annual-mean $\operatorname{SST}_{\mathrm{SIO}}\left(R^{2}=0.097, p=\right.$ 0.004 ) and was not further considered as a predictor.

We first fit a linear regression to the annual-mean SST (response) with the PDO (predictor) from the start of each time series through 1987 (i.e., the last full year the old pier was in use), then predicted the annual-mean SST over the entire time series (e.g., 1916-present for SIO), and finally computed the residuals between pre-

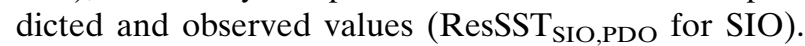
This was done for each time series (Table 3). We applied two statistical methods for identifying discontinuities: (i) the sequential $t$ test analysis of regime shifts (STARS) with a significance value $p$ of 0.01 and a cutoff length of $10 \mathrm{yr}$ (Rodionov 2004) and (ii) a generalized fluctuation test based on the cumulative sum of recursive residuals of ordinary least squares residuals (OLS-CUSUM) with 95\% confidence intervals (Brown et al. 1975; Ploberger and Krämer 1992). Neither method makes an a priori assumption about the existence of discontinuities. We also investigated whether the relationship between annual-mean SST $_{\text {SIO }}$ and the PDO remained stable throughout the period by estimating the intercept and slope of the linear regression (as described above) over a sliding window of $10 \mathrm{yr}$ for the entire period.
To assess whether detrending in computing the PDO (Mantua et al. 1997) affects our results, we subtracted annual values of the global annual-mean SST anomaly (http://www.ncdc.noaa.gov/cag/time-series/global), used to calculate the PDO, from the annual-mean $\mathrm{SST}_{\mathrm{SIO}}$. We used the same subset of global SST anomaly observations as used by Mantua et al. (1997). This grid file is available online (at ftp://ftp.atmos.washington.edu/ mantua/pdofiles/grid.temp.glob_ocean.977). We then repeated our analyses using the PDO as the predictor and STARS and OLS-CUSUM as the test types.

We created a second predictor using time series of annual-mean SST from other shore stations. For each annual-mean SST time series (response), the first principal component $\left(\mathrm{PC}_{\mathrm{SS}}\right)$ of all the remaining times series (10 or 11) was used as a predictor variable (Table 4). We excluded SIO and San Clemente (SC) due to discontinuities based on the STARS and OLSCUSUM analyses. Residuals were computed as described above but using $\mathrm{PC}_{\mathrm{SS}}$ (e.g., ResSST $\mathrm{SIO}_{\mathrm{SS}}$ for SIO) and tested for discontinuities using STARS and OLS-CUSUM.

To measure the variation of $\mathrm{SIO}_{\mathrm{SST}}$ on the scale of minutes, we created the continuous sea surface temperature (CSST) instrument (Fig. 2). The CSST instrument consists of two floats connected by an articulated arm. The vertical float tracks the water surface while surrounding a plastic-coated wire suspended through the same opening in the SIO pier through which the standard SST $_{\text {SIO }}$ bucket sample is taken and held taut by a $10-\mathrm{kg}$ weight $1 \mathrm{~m}$ above the bottom. The horizontal float has a data logger with temperature sensor (Onset U12-015-02) attached to its lower surface. The sensor has a 25 -s response time, and temperature is recorded every minute

TABLE 2. Model selection. Based on likelihood ratio tests and Akaike Information Criterion (AIC) scores (Akaike 1974). $R_{\text {adj }}^{2}$ (adjusted $\left.R^{2}\right)$ is explained variance, $p$ is significance of the likelihood ratio test, and $N$ is degrees of freedom. Number 4 is the final model. MEI was excluded during model fitting $(r=0.62, n=93$, and $p<0.0001)$ due to colinearity with the PDO.

\begin{tabular}{|c|c|c|c|c|c|}
\hline No. & Model & AIC & $R_{\mathrm{adj}}^{2}(\%)$ & $p$ & $\bar{N}$ \\
\hline 1 & $\mathrm{SST}_{\mathrm{SIO}} \sim \alpha+\mathrm{PDO}+\mathrm{SOI}+\mathrm{NPGO}+\mathrm{NOI}+\varepsilon$ & 53.1 & 48.4 & & 33 \\
\hline 2 & $\mathrm{SST}_{\mathrm{SIO}} \sim \alpha+\mathrm{PDO}+\mathrm{SOI}+\mathrm{NPGO}+\varepsilon$ & 51.1 & 49.9 & 0.94 & 34 \\
\hline 3 & $\mathrm{SST}_{\mathrm{SIO}} \sim \alpha+\mathrm{PDO}+\mathrm{NPGO}+\varepsilon$ & 49.1 & 51.4 & 0.98 & 35 \\
\hline 4 & $\operatorname{SST}_{\mathrm{SIO}} \sim \alpha+\mathrm{PDO}+\varepsilon$ & 47.8 & 51.8 & 0.42 & 36 \\
\hline
\end{tabular}


TABLE 3. Sea surface temperature sources and regressions of SST on PDO. Annual-mean SST data sources. Some time series have gaps; see Fig. 3. Intercept, slope, and explained variance $\left(R^{2}\right)$ of linear regression models fitting SST to PDO through 1987. All intercepts and slopes are significant at $p<0.001$, with the exception of CHA slope (not significant).

\begin{tabular}{|c|c|c|c|c|c|}
\hline SST time series & Location & Dates & Intercept & Slope & $R^{2}$ \\
\hline $\mathrm{SIO}$ & Scripps, CA & 1916-2010 & 16.94 & 0.49 & 0.48 \\
\hline $\mathrm{SC}$ & San Clemente, CA & $1955-2010$ & 16.58 & 0.49 & 0.32 \\
\hline NP & Newport Beach, CA & 1925-2010 & 16.43 & 0.53 & 0.49 \\
\hline SM & Santa Monica, CA & 1946-2001 & 16.80 & 0.82 & 0.66 \\
\hline PD & Point Dume, CA & 1975-2010 & 15.77 & 0.66 & 0.55 \\
\hline SB & Santa Barbara, CA & 1946-2010 & 15.85 & 0.49 & 0.60 \\
\hline MB & Morro Bay, CA & $1962-96$ & 13.37 & 0.72 & 0.62 \\
\hline PG & Pacific Grove & 1919-2010 & 13.07 & 0.34 & 0.23 \\
\hline FAR & Farallon Islands, CA & 1925-2010 & 12.24 & 0.42 & 0.28 \\
\hline $\mathrm{BB}$ & Bodega Bay, CA & 1957-2001 & 11.45 & 0.58 & 0.53 \\
\hline $\mathrm{CC}$ & Crescent City, CA & 1933-2001 & 12.02 & 0.62 & 0.55 \\
\hline $\mathrm{CHA}$ & Charleston, OR & $1966-97$ & 11.30 & 0.20 & 0.12 \\
\hline NB & Neah Bay, WA & 1935-2001 & 9.71 & 0.38 & 0.49 \\
\hline ERSST & Southern California* & 1854-2010 & 16.03 & 0.21 & 0.11 \\
\hline CalCOFI & Southern California** & 1950-2010 & 13.73 & 0.49 & 0.31 \\
\hline
\end{tabular}

* See grid boxes in McClatchie et al. (2010).

** CalCOFI lines 76.7-93.3, 5-15-m depth.

to $0.01^{\circ} \mathrm{C}$. Visual observations from above and in the water showed the temperature sensor to be $1-4 \mathrm{~cm}$ below the sea surface, thus measuring the "true bulk" SST (cf. Webster et al. 1996). SST from the bucket sample and CSST instrument were indistinguishable.

The CSST instrument was deployed 7-10 July 2014 from the SIO pier. Air temperature and water level relative to mean lower low water (MLLW) at the SIO pier were recorded every $6 \mathrm{~min}$ and available from the National Oceanic and Atmospheric Administration (NOAA) (http://tidesandcurrents.noaa.gov/stationhome. html?id=9410230). Significant wave height $\left(H_{S}\right.$; the average of the $1 / 3$ of the highest waves) every hour at the SIO pier was available from the Coastal Data Information Program (http://cdip.ucsd.edu/?ximg $=$ search \& xsearch $=073 \&$ xsearch_type $=$ Station_ID). A double running-mean procedure (zero-phase digital filter) was used to smooth the time series of SST $_{\mathrm{SIO}}$ from the CSST instrument using averaging windows of four lengths (30-240 min). Power spectra were computed for the time series of residuals. The same data logger with the temperature sensor as used on the CSST instrument was lowered from the SIO pier and submerged completely at multiple locations in the surf zone on 14 July 2014. These measurements were compared with $\mathrm{SST}_{\mathrm{SIO}}$ measured immediately afterward using the CSST instrument to test the hypothesis that water in the surf zone is warmer than $\mathrm{SST}_{\text {SIO }}$.

Statistical analyses were conducted using the R software version 2.12.1 (www.r-project.org), Matlab (R2013b, MathWorks, Natick, Massachusetts), and the Excel addin software for STARS (www.beringclimate.noaa.gov).

\section{Results}

The PDO and $\mathrm{PC} 1_{\mathrm{Ss}}$ accounted for significant variability in annual-mean SST at stations along the U.S. West Coast through 1987, with highly significant linear regression parameters overall (Tables 3,4), except for a nonsignificant slope for Charleston (CHA) and the PDO (Table 3). Regression slope did not vary with shore station latitude (Kendall's rank correlation, $\tau=$ $-0.10, p=0.67$, and $n=13$ ), while the intercept decreased significantly with increasing latitude $(\tau=-0.90$, $p \sim 0$, and $n=13$ ).

TABLE 4. Regressions of SST on PC1 of Shore Stations SST. $N$ is number of SST time series used in PCA. Intercept, slope, and explained variance $\left(R^{2}\right)$ of linear regression models fitting annualmean SST to PC1 of SST for $N$ shore stations through 1987 (see Table 3 for locations). For all cases intercept and slope are significant $p<0.001$.

\begin{tabular}{lllll}
\hline \hline SST time series & $N$ & Intercept & Slope & $R^{2}$ \\
\hline SIO & 11 & 17.45 & 3.78 & 0.72 \\
SC & 11 & 16.70 & 3.32 & 0.55 \\
NP & 10 & 16.52 & 3.91 & 0.75 \\
SM & 10 & 16.79 & 5.81 & 0.83 \\
PD & 10 & 15.78 & 4.68 & 0.73 \\
SB & 10 & 15.84 & 3.40 & 0.74 \\
MB & 10 & 13.35 & 4.56 & 0.69 \\
PG & 10 & 13.36 & 3.40 & 0.79 \\
FAR & 10 & 12.42 & 3.56 & 0.45 \\
BB & 10 & 11.43 & 4.04 & 0.70 \\
CC & 10 & 11.99 & 3.71 & 0.49 \\
CHA & 10 & 11.30 & 1.80 & 0.36 \\
NB & 10 & 9.69 & 2.59 & 0.59 \\
ERSST & 11 & 13.80 & 3.53 & 0.48 \\
CalCOFI & 11 & 16.20 & 1.42 & 0.16 \\
\hline
\end{tabular}




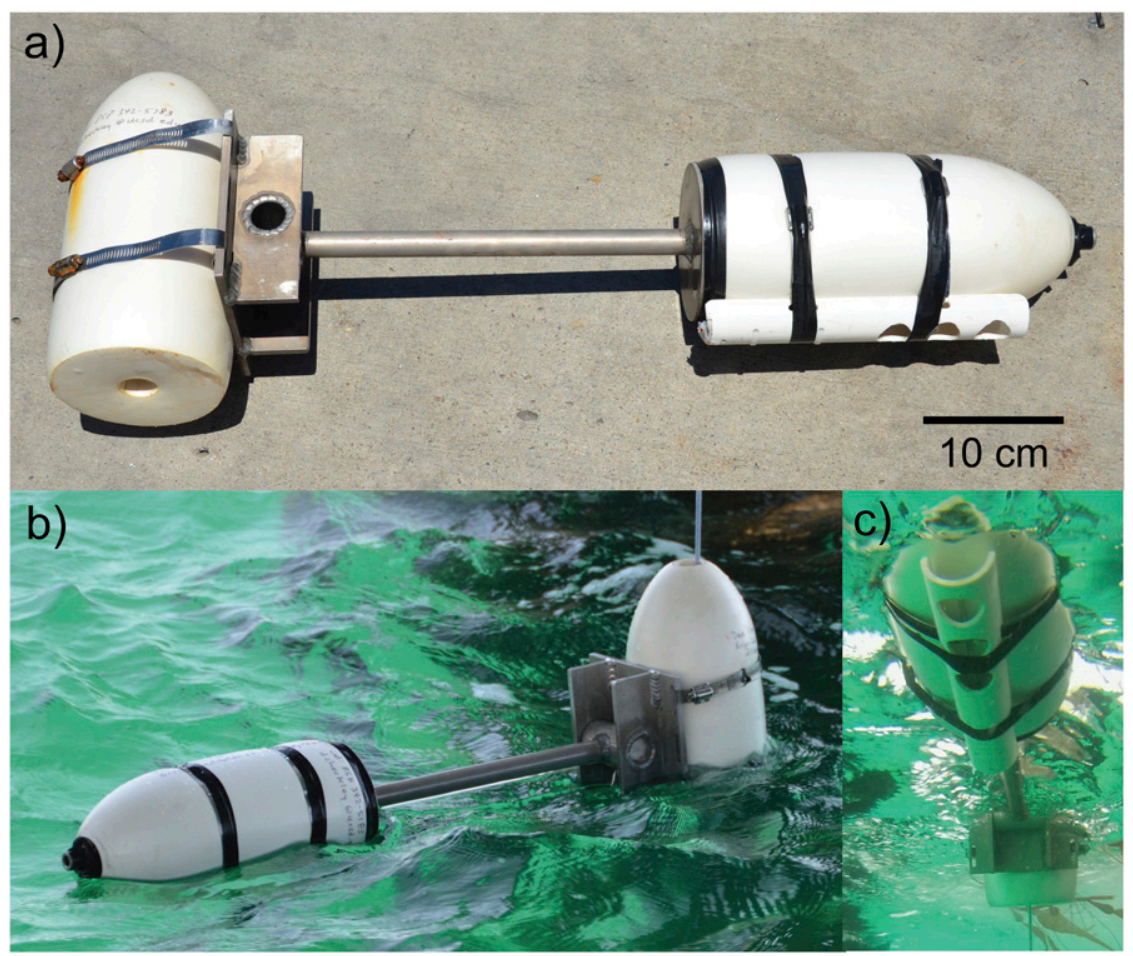

FIG. 2. CSST instrument. (a) On SIO pier. (b) In water below SIO pier. (c) Image taken in the water showing submerged probe. Vertically oriented float rides on plastic-coated wire suspended from SIO pier and with 10-kg weight $1 \mathrm{~m}$ above the ocean bottom. Horizontal float has HOBO U12 stainless 5" probe temperature logger (Onset U12-015-02) attached to the underside, shielded by PVC, and is attached to vertical float by an aluminum rod by a rotary joint that allows motion in the vertical plane. Periodic visual observation from above and below the sea surface during 3 day deployment $7-10$ Jul 2014 showed the probe to be 1-4 cm below the sea surface and not exposed to air.

Our response variable was annual-mean SST (Fig. 3). We used two predictors, the PDO and $\mathrm{PC} 1_{\mathrm{SS}}$, and two test types, STARS and OLS-CUSUM. This resulted in four tests of our hypothesis. We first present results for $\mathrm{PDO}$ as the predictor, followed by those using $\mathrm{PC}_{\mathrm{Ss}}$.

\section{a. Test 1: PDO and STARS}

ResSST $_{\mathrm{XXX}, \mathrm{PDO}}(\mathrm{xxx}$ denotes an individual shore station) (Table 3) fluctuates around zero for all stations (Figs. 1b, 4), except for SIO and SC for which STARS show significant positive discontinuities in 1988 and 1983, respectively. The significant discontinuities for Pacific Grove (PG) and ERSST.v3b (ER) residuals in $\sim 1928$ are likely due to edge effects caused by low mean values at the start of both time series.

\section{b. Test 2: PDO and OLS-CUSUM}

The OLS-CUSUM test identified significant change points in ResSST SIO,PDO $_{\text {(1988; Figs. 5a, 6) and }}$ ResSST $_{\text {SC,PDO }}$ (1988; Fig. 6) that manifest as troughs, consistent with the STARS analysis. The other OLS-CUSUM plots using PDO as the predictor show fluctuations largely within the confidence intervals, except for PG and ER during the 1930s (Fig. 6). These results are insensitive to the regression period; for example, the same discontinuity was detected when the predictor was based

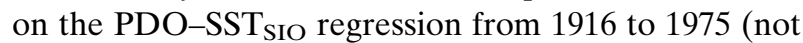
shown) rather than 1916 to 1987.

The results using the PDO as predictor (STAR and OLS-CUSUM) were unchanged when the response variable was the annual-mean SST $_{\mathrm{SIO}}$ - global annual-mean SST anomaly (see Fig. S1 in the supplemental material).

\section{c. Test 3: $P C 1_{S S}$ and STARS}

Using $\mathrm{PC}_{\mathrm{SS}}$, instead of the PDO, as the predictor

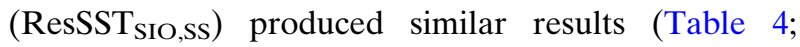
Figs. 5b, 7). Regression of annual-mean SST on PC1 $1_{\mathrm{SS}}$ was highly significant for all shore stations (Table 4). STARS shows ResSST SIO,ss with a positive discontinuity in 1992 (Fig. 7a); we note that the time series was $54 \mathrm{yr}$ long, due to length limitations of the other shore station SST time series (Table 3). The only other shore 

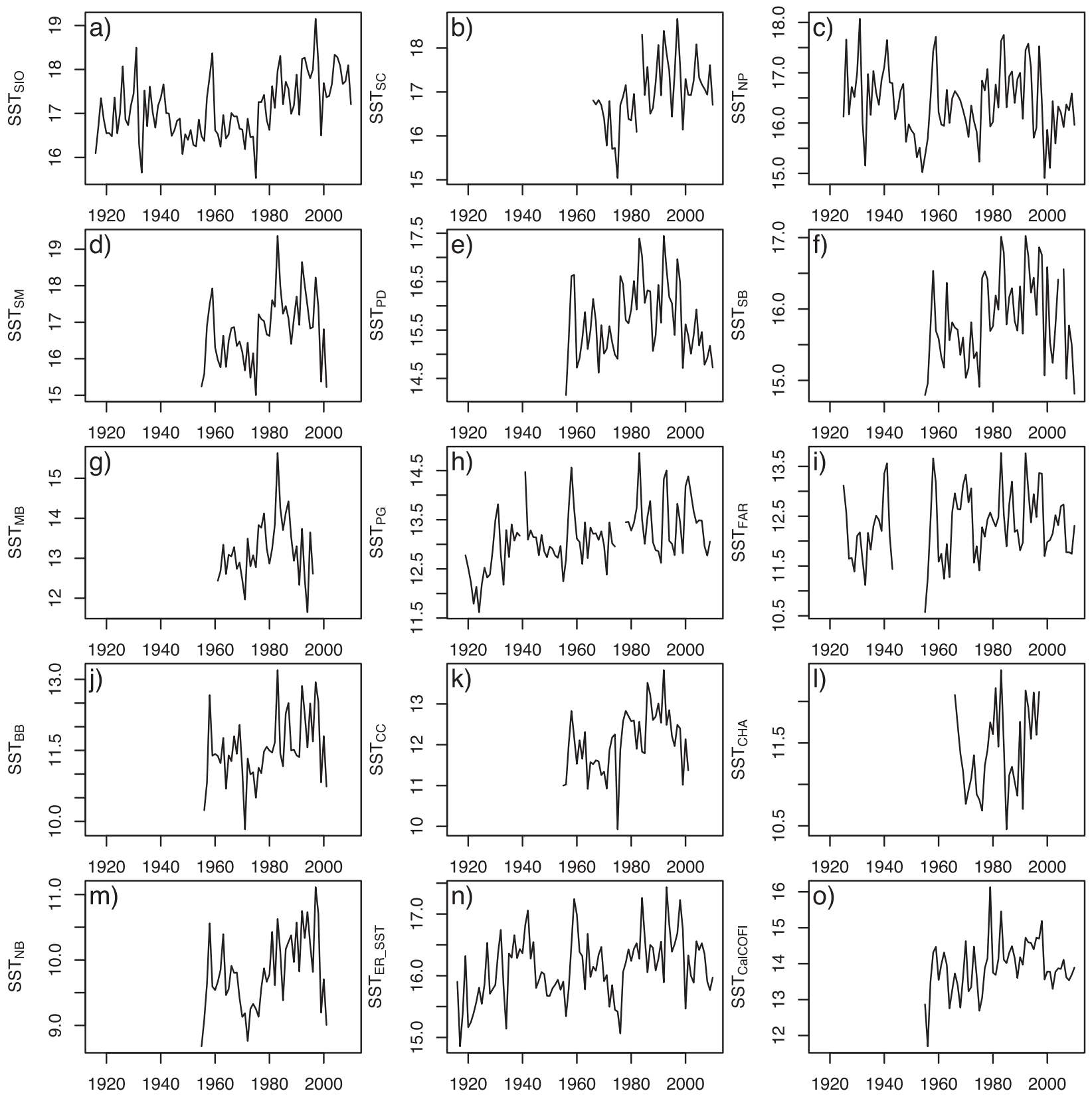

FIG. 3. Annual-mean SST (SST ${ }_{\mathrm{XXX}}$, where $\mathrm{xxx}$ is SST time series abbreviation) for shore stations ranging from (a)-(m) Southern California to the state of Washington, as well as from (n)-(o) nearby offshore waters. (See Table 3 for time series abbreviations.)

station to have a significant discontinuity using $\mathrm{PC} 1_{\mathrm{SS}}$ and STARS was SC in 1983 (Fig. 7b).

\section{d. Test 4: $\mathrm{PC1}_{S S}$ and $O L S-C U S U M$}

Using the $\mathrm{PC}_{\mathrm{SS}}$ as the predictor, OLS-CUSUM has a broad trough from $\sim 1982$ to 1995 (Figs. 5b, 8a); again, the time series was $54 \mathrm{yr}$ long. Shore stations, in addition to SIO, having significant troughs using $\mathrm{PC}_{\mathrm{SS}}$ and OLS-CUSUM were SC ( 1982-88) and Neah Bay
(NB), Washington (1986-87); Morro Bay (MB), California, had a significant peak in 1988 (Fig. 8).

The intercept and slope of the linear regression for annual-mean SST $_{\text {SIO }}$ on PDO, using a 10-yr sliding window, fluctuate throughout the period (Figs. 5c,d). However, only the intercept shows a significant change, following its abrupt increase in 1988 (Fig. 5c).

Results from deployment of the CSST instrument and ancillary data are shown in Fig. 9. Three complete diel 

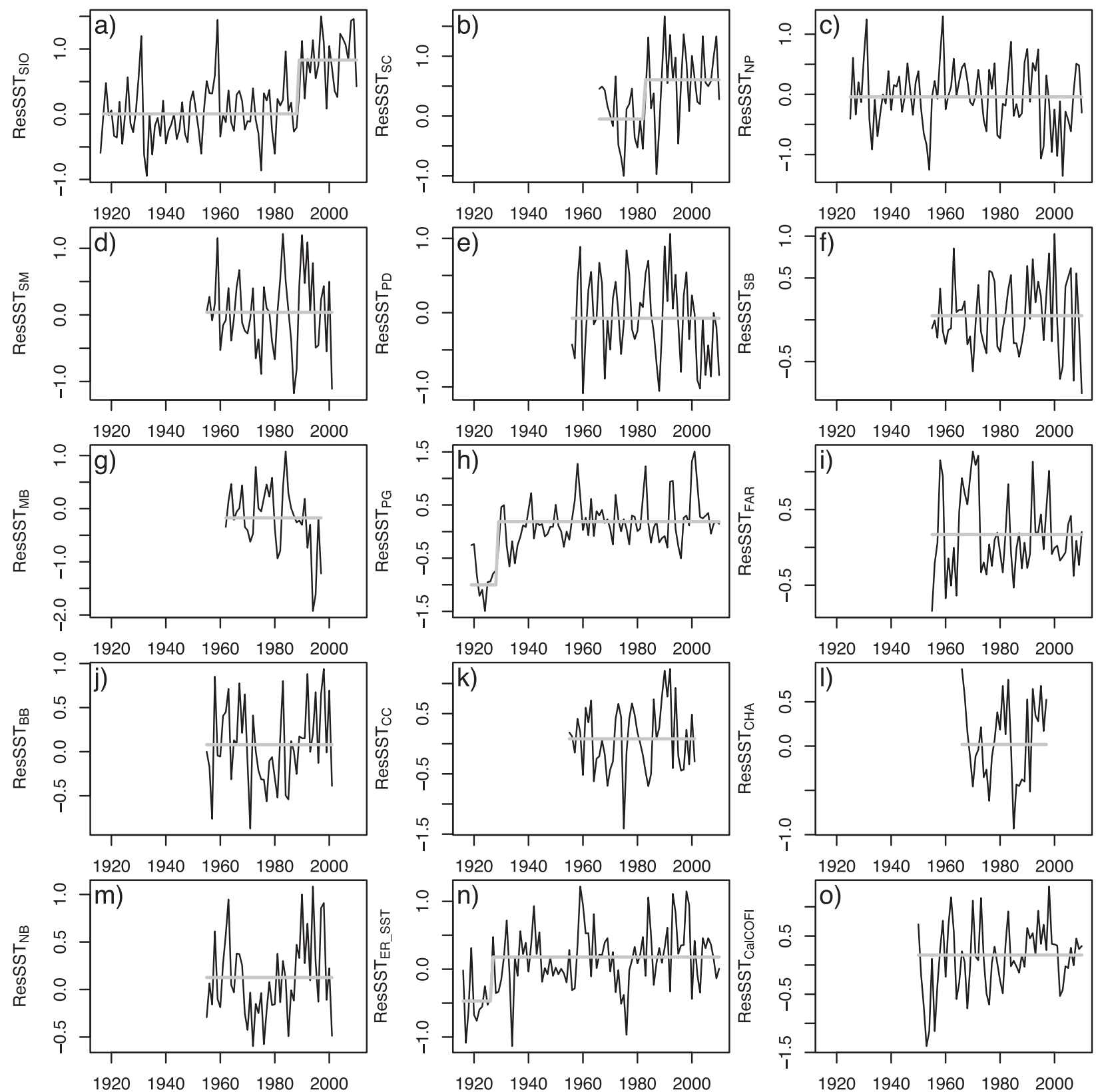

FIG. 4. Annual-mean residuals (ResSST $\mathrm{XXX}_{\mathrm{XDO}}$, where $\mathrm{XxX}$ is SST time series abbreviation) of observed SST from SST predicted from PDO using linear regressions of SST on the PDO until 1987 for (a)-(m) shore stations and (n)-(o) offshore SST time series. Significant discontinuities in ResSST detected by STARS are shown in gray. (See Table 3 for time series abbreviations.)

cycles were observed. Air temperature increased after sunrise and began to decline in midafternoon each day. Both water level and significant wave height varied moderately. SST $_{\text {SIO }}$ measured by the CSST instrument showed a strong diel variation, minimal near sunrise and maximal near sunset. Notable were pulses of warming during the daytime. SST $_{\text {SIO }}$ from standard bucket sampling and the CSST instrument were indistinguishable (Fig. 9d; red crosses and black line, respectively). Time series of residuals (unfiltered-filtered $\mathrm{SST}_{\mathrm{SIO}}$ from CSST instrument) for averaging windows of 30-240 min (Figs. 9e and 9f, respectively) show the greatest variability during daylight. Power spectra of these time series (Fig. 10) show an abrupt increase in power for periods $40 \mathrm{~min}$ and greater. Measurements on 14 July 2014 between 1412 and 1727 LT showed water in the surf zone to be significantly (Student's $t$ test, $p<0.0001)$ warmer $(23.21 \pm$ $0.01^{\circ} \mathrm{C}$, mean \pm standard error, and $\left.n=52\right)$ than $\mathrm{SST}_{\mathrm{SIO}}$ 

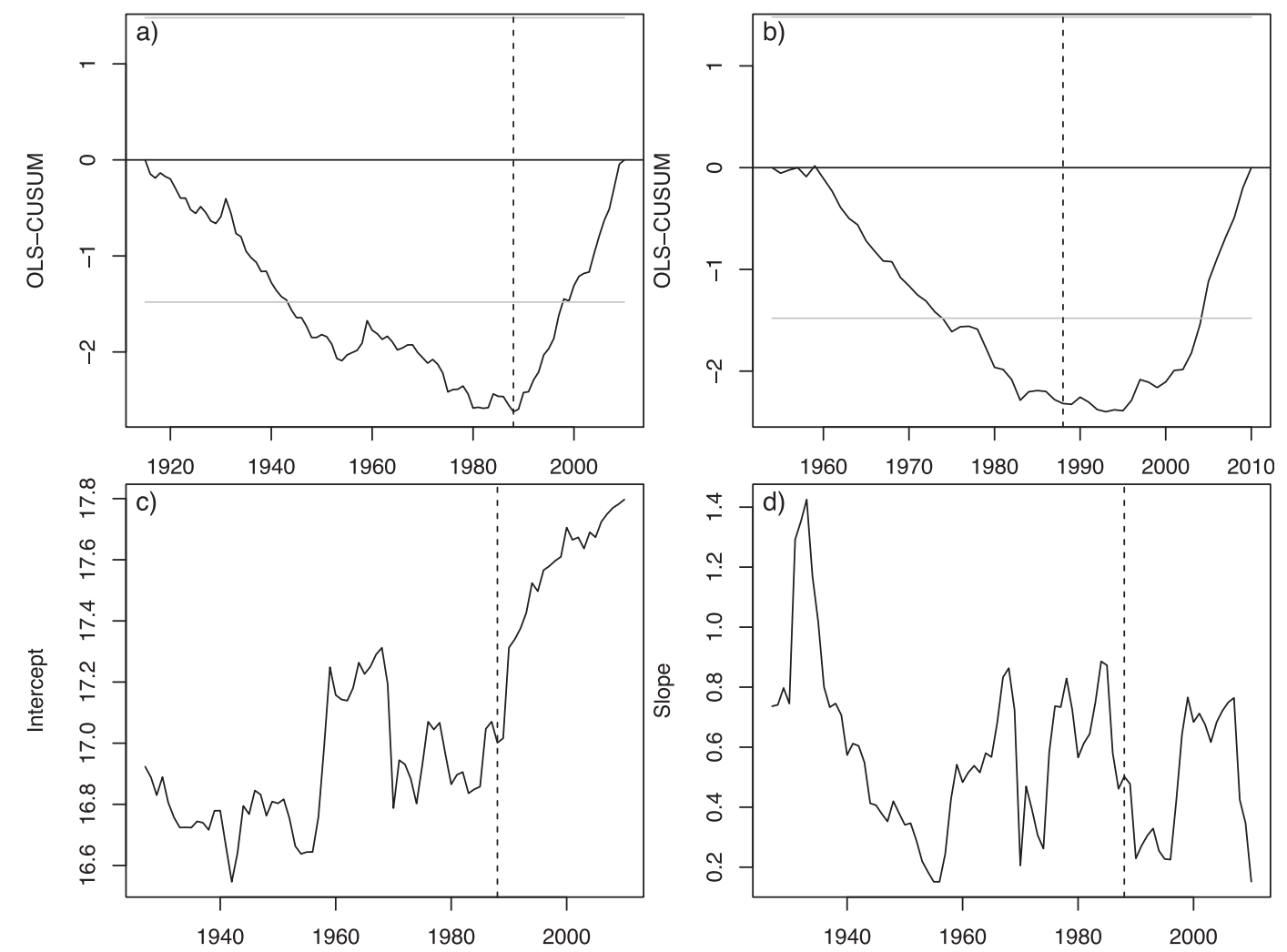

FIG. 5. OLS-CUSUM based on (a) ResSST SIO,PDO $_{\text {and (b) ResSST }}$ SIO,Ss. (c) Intercept and (d) slope of a linear regression of $\mathrm{SST}_{\mathrm{SIO}}$ on PDO using a sliding window of $10 \mathrm{yr}$. Vertical black dashed lines indicate SIO pier change in 1988.

$\left(22.53 \pm 0.01^{\circ} \mathrm{C}, n=27\right)$. During this period, air temperature was $20.4^{\circ} \mathrm{C}$ and $H_{S}$ was $0.6 \mathrm{~m}$.

\section{Discussion}

We assume that the water temperature has been measured accurately and hence is comparable over the entire time series at SIO and elsewhere. At SIO, the same protocol has been used to collect water since 1916 . The change from mercury to digital thermometers was gradual over the period 2008-10. Thus, we conclude that changes in temperature are not due to measurement error. We also assume that the SST time series at other shore stations are comparable (cf. McGowan et al. 1998).

STARS and OLS-CUSUM tests show a positive discontinuity in ResSST, based on the PDO, in 1988 at SIO but not at other shore stations to the north. The 1988 discontinuity based on the PDO remains when the global annual-mean SST is subtracted from the annualmean $\mathrm{SST}_{\mathrm{SIO}}$, consistent with the discontinuity not having resulted from detrending in the PDO calculation (Mantua et al. 1997). Both types of tests are sensitive to the length and period of the time series. When the predictor was PC1 of the annual-mean SST time series for shore stations to the north (excluding SC), STARS showed a discontinuity in 1992 (Fig. 7a) and OLS-CUSUM a broad trough from $\sim 1982$ to 1995 (Figs. 5b, 8). We attribute the different results using the PDO and $\mathrm{PC} 1_{\mathrm{SS}}$ to lesser precision associated with the shorter time series (54 yr) used to compute PC1 $1_{\mathrm{Ss}}$, compared with the longer time series for $\mathrm{SST}_{\mathrm{SIO}}$ and PDO (95 yr). In addition, there are other unaccounted sources of variation in the shore station SST time series and thus $\mathrm{PC}_{\mathrm{SS}}$. The abrupt increase in the intercept, but not the slope, of the regression of annual-mean SST $_{\text {SIO }}$ on the PDO (Figs. 5c and $5 \mathrm{~d}$, respectively) is also consistent with an abrupt increase in annual-mean SST $_{\text {SIO }}$ in 1988. Collectively, these results are consistent with a change in 1988 of SST measured at the SIO pier but not at other locations, with the exception of SC.

SST $_{\text {SIO }}$ measured every minute by the CSST instrument during the period 7-10 July 2014 varied on a diel cycle and at shorter time scales, manifest by pulses of warming (Figs. 9d, 10). Daytime increase in SST is common (e.g., Webster et al. 1996; Prytherch et al. 
SIO
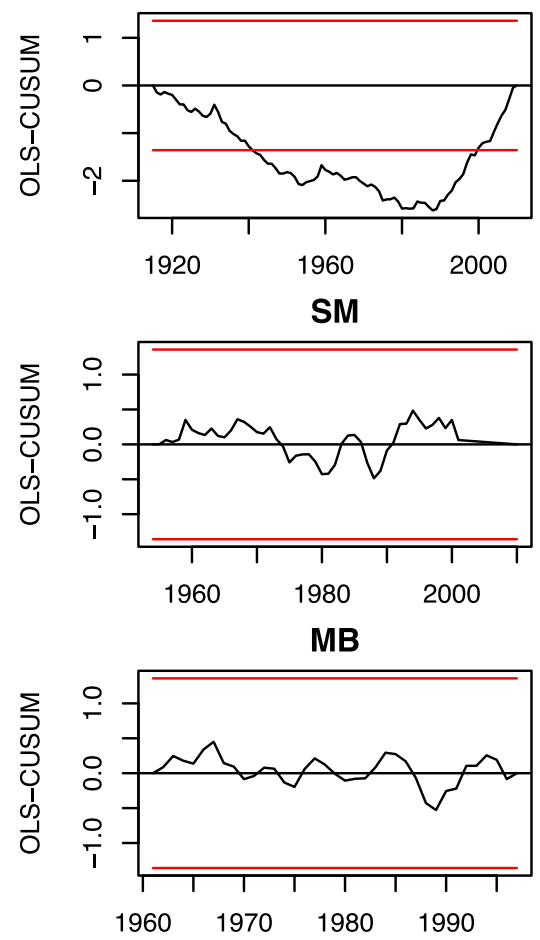

BB

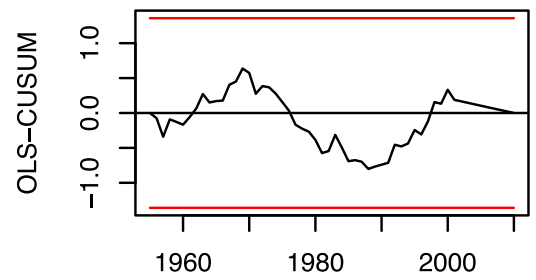

NB

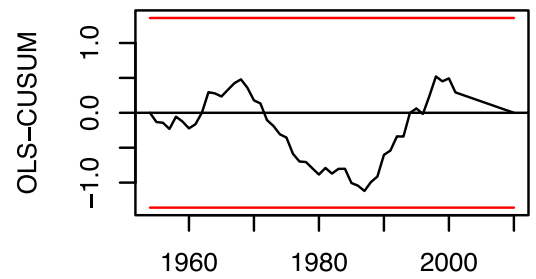

SC
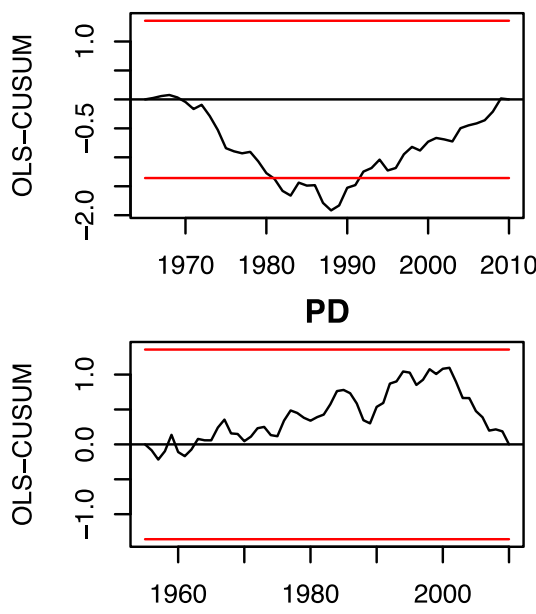

$P G$

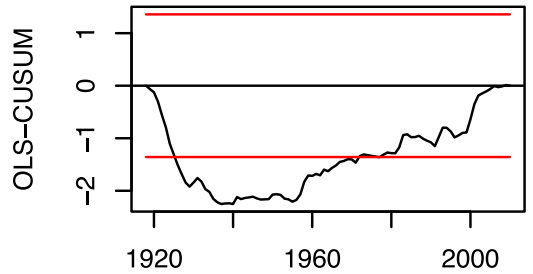

CC

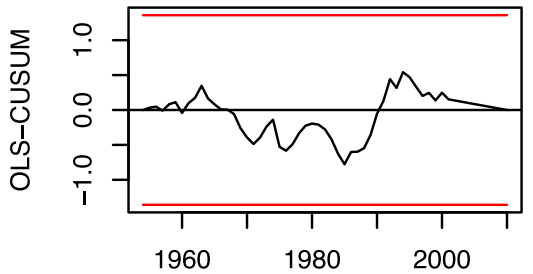

ER SST

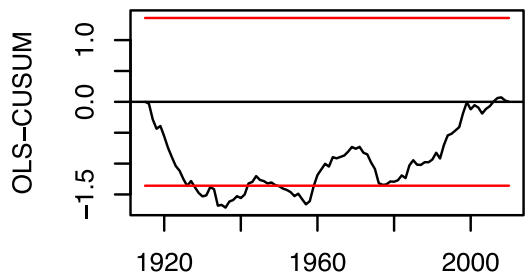

NP

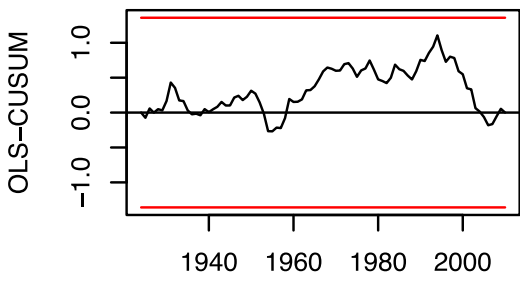

SB

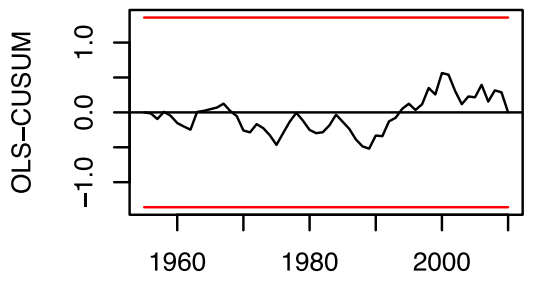

FAR

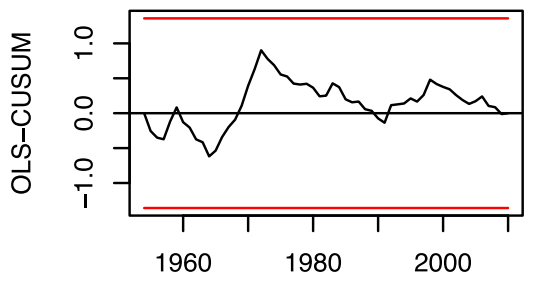

CHA

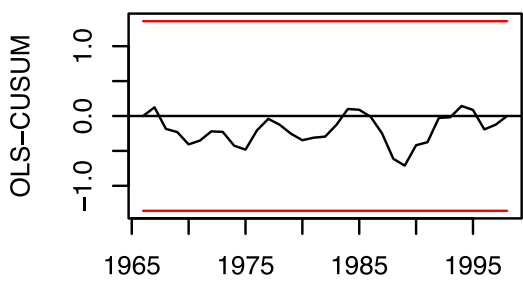

CalCOFI

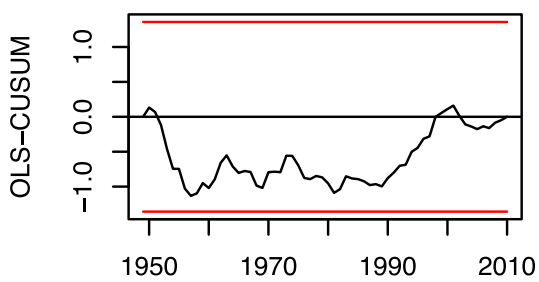

FIG. 6. OLS-CUSUM of residual SST time series based on the PDO (ResSST XxX,PDO, where $_{\mathrm{Xxx}}$ is SST time series abbreviation). Red solid lines indicate $95 \%$ confidence intervals. (See Table 3 for time series abbreviations.)

2013), due to daytime increases in the fluxes of sensible heat and shortwave radiation into the ocean. Overlaid on this gradual increase were distinct pulses of warming, notable in the time domain for both $\mathrm{SST}_{\mathrm{SIO}}$ (Fig. 9d) and residuals from the smoothed time series of $\mathrm{SST}_{\mathrm{SIO}}$ (Figs. 9e-h). Power spectra of the residuals show an abrupt increase in variance at periods equal to and greater than $40 \mathrm{~min}$ (Fig. 10). Monthly averages of daily power spectra of high-passed, near-surface temperature measured at the end of the SIO pier during 2011 also peaked at $\sim 40 \mathrm{~min}$ (Figs. S2 and S3 in the supplemental material). Such variability is consistent with that previously observed for rip currents near the SIO pier (Smith and Largier 1995). Measurements made 14121727 LT 14 July 2014 showed water in the surf zone to be $\sim 0.7^{\circ} \mathrm{C}$ warmer than $\mathrm{SST}_{\mathrm{SIO}}$, despite the air being cooler than the water and thus the flux of sensible heat being from the ocean to the atmosphere, indicating shortwave radiation as the cause of ocean heating. Shortwave radiation heats the surf zone both directly by heating the 

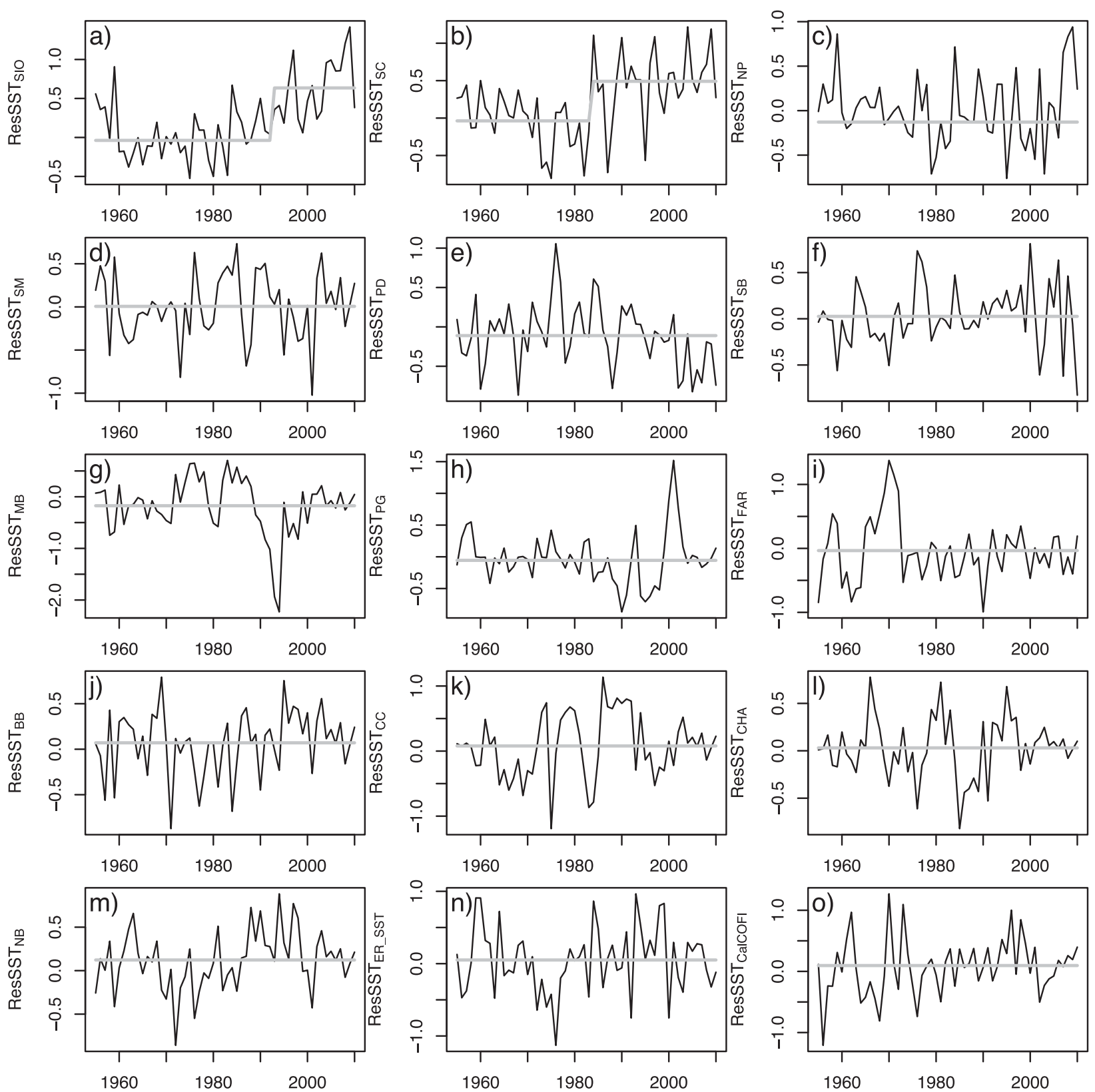

FIG. 7. Annual-mean residuals (ResSST $\mathrm{XxX,Ss}$, where $\mathrm{xxx}$ is SST time series abbreviation) of observed SST from SST predicted from PC1 of other shore station time series using linear regressions of annual-mean SST on PC1 until 1987 for (a)-(m) shore stations and (n)-(o) offshore SST time series. Significant discontinuities in ResSST detected by STARS are shown in gray. [See Table 3 for time series abbreviations and number of shore station time series used in each principal component analysis (PCA).]

water and indirectly by heating the beach that in turn heats the water during wave runup (Stockdon et al. 2006) and flood tide. Enhanced flow by rip currents of surf-zone water warmer than the surface water near the end of the pier, where SST $_{\text {SIO }}$ is measured, will act as a buoyant surface jet (cf. Jirka et al. 1981) and contribute to warmer $\mathrm{SST}_{\text {SIO }}$. Enhanced flow by rip currents of surf-zone water cooler than surface water near the end of the pier will act as a negatively buoyant jet and sink beneath warmer, less dense surface water and not affect $\operatorname{SST}_{\text {SIO }}$ (cf. Saeedi et al. 2012). We assume the forcing of rip currents is positively related to significant wave height $H_{S}$, which does not vary on a diel cycle (e.g., Fig. 9c). Our observations of diel variation in $\mathrm{SST}_{\mathrm{SIO}}$ and ResSST $\mathrm{SIO}$ (Figs. 9d-h) showing greater high-frequency variability during the day than night 
SIO

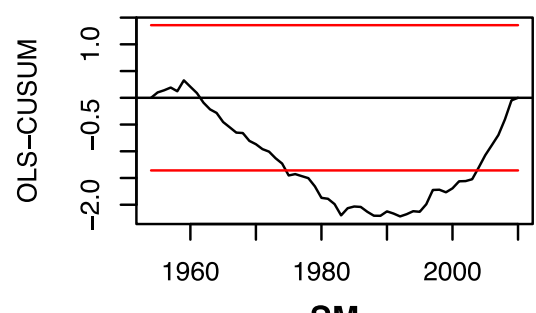

SM

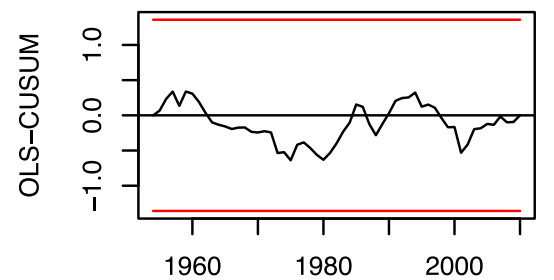

MB

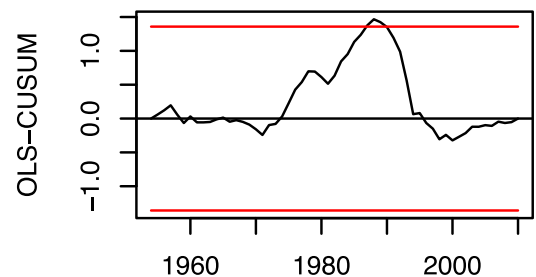

BB

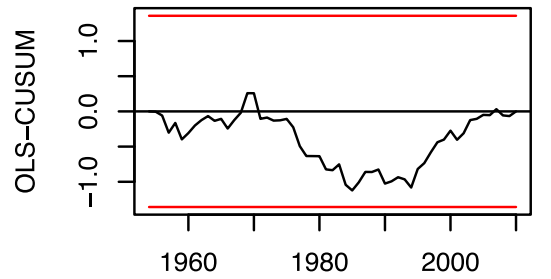

NB

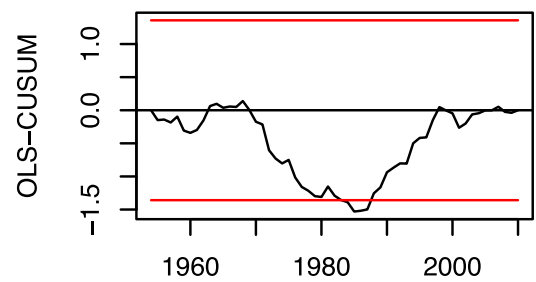

SC

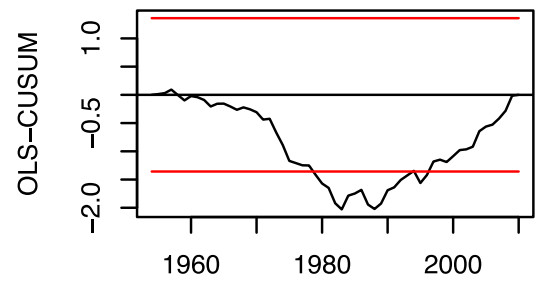

PD

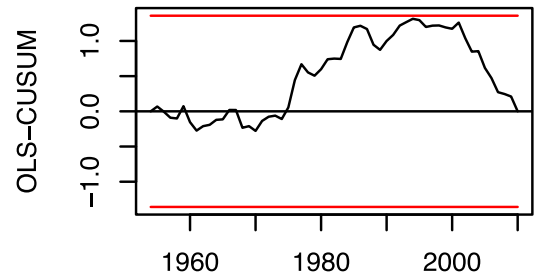

PG

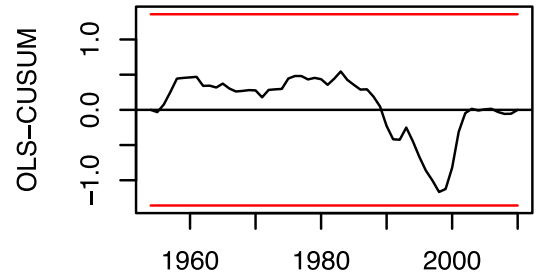

CC

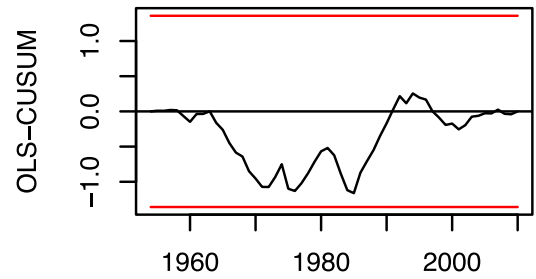

ERSST

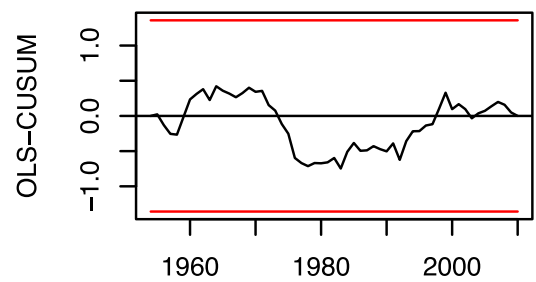

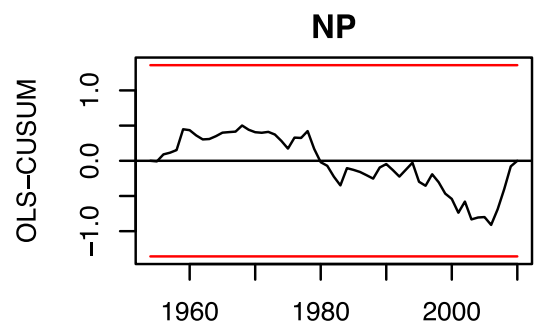

SB
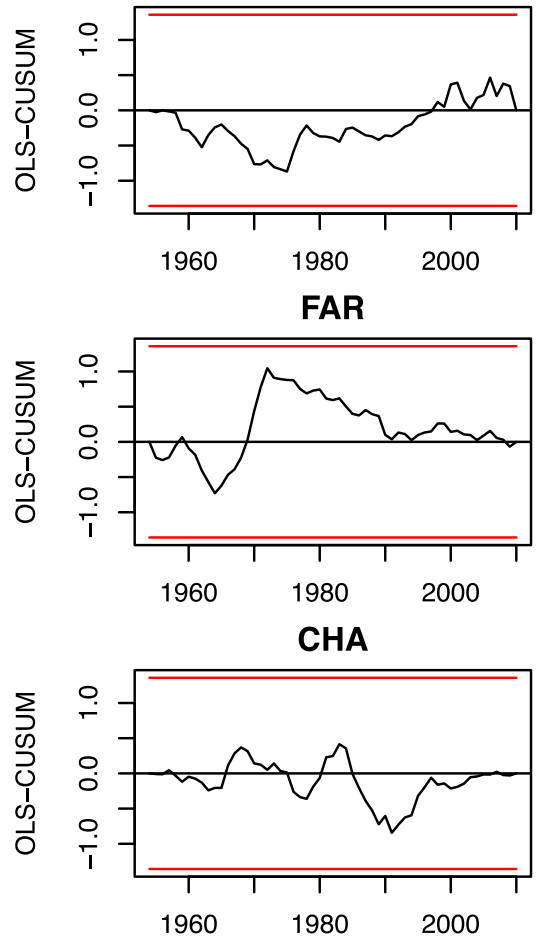

CalCOFI

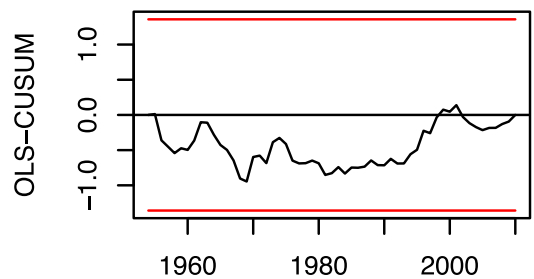

FIG. 8. OLS-CUSUM of residual annual-mean SST time series based on the PC1 of other shore station time series (ResSST XXX,SS, where $\mathrm{xxx}_{\mathrm{x}}$ is SST time series abbreviation). Red solid lines indicate $95 \%$ confidence intervals. (See Table 3 for time series abbreviations and number of shore station time series used in each PCA.)

are consistent with rip currents occurring during both day and night but affecting $\mathrm{SST}_{\mathrm{SIO}}$ primarily during the day.

Rip currents are associated with piers due to bottom scouring around pilings and reduced surface wave energy (Haller et al. 2002; MacMahan et al. 2006; Dalrymple et al. 2011; Farahani et al. 2014). Preliminary observations show the bottom depth beneath the outer $\sim 50 \mathrm{~m}$ of the present SIO pier to be approximately one meter deeper than adjacent depths (Fig. S4 in the supplemental material), consistent with bottom scouring associated with the pier pilings.

Collectively, our results indicate rip currents transport relatively warm water from the surf zone to the location where $\mathrm{SST}_{\mathrm{SIO}}$ is measured. Our results are also consistent with prior observations of rip currents at the present SIO pier (Smith and Largier 1995; Chang and Twardowski 2011; Twardowski et al. 2012). 

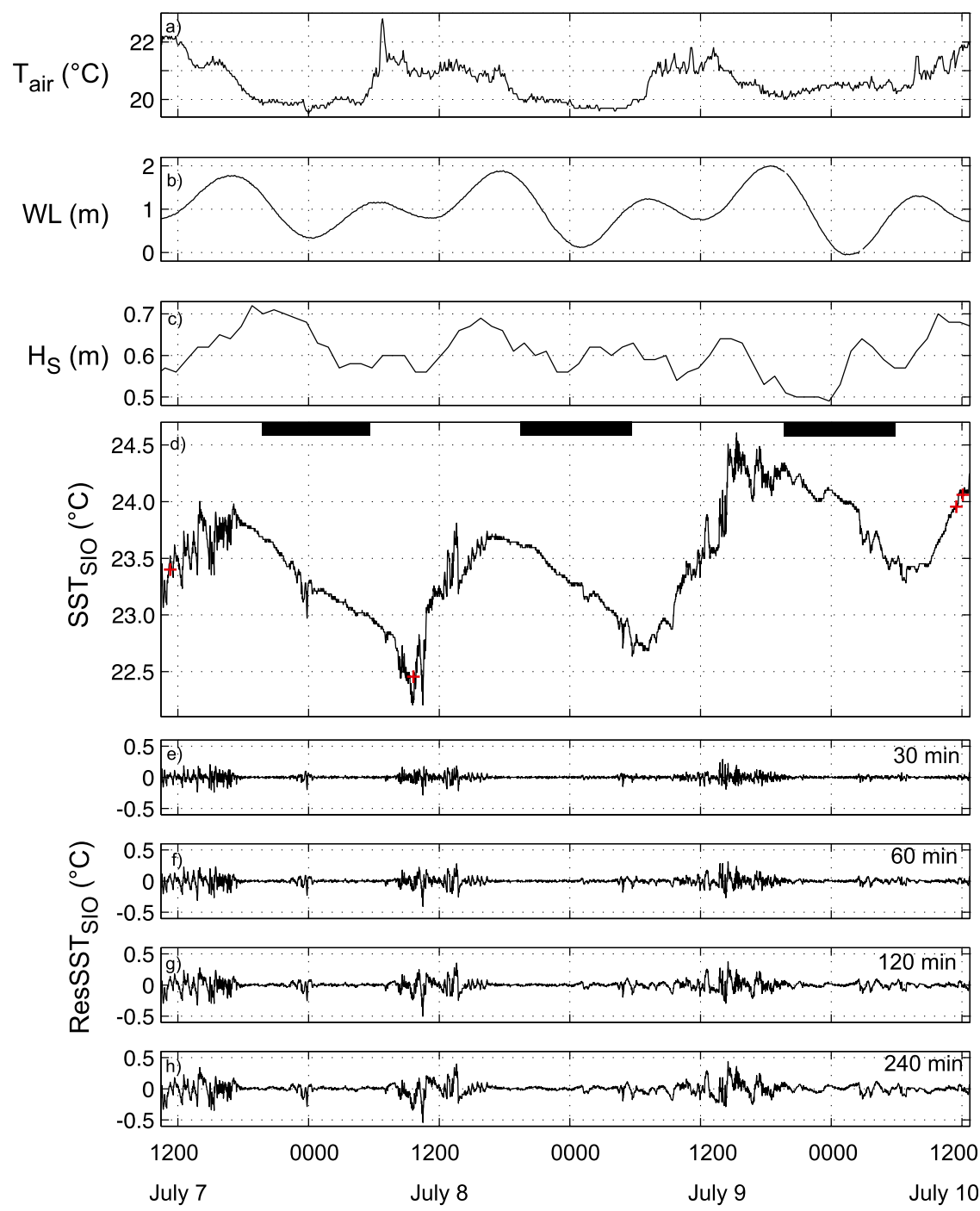

Date (2014)

FIG. 9. SST measured from SIO pier by CSST instrument and related variables. (a) Air temperature $\left({ }^{\circ} \mathrm{C}\right)$. (b) Water level $(\mathrm{m})$. (c) Significant wave height $(\mathrm{m})$. (d) $\operatorname{SST}_{\mathrm{SIO}}\left({ }^{\circ} \mathrm{C}\right)$ from CSST (black line) and standard bucket sample (red cross). Black bars denote sunset to sunrise. (e)-(h) Residual of $\mathrm{SST}_{\text {SIO }}$ (d) minus double running mean of $\mathrm{SST}_{\text {SIO }}$ computed using windows of $30,60,120$, and 240 values $(\mathrm{min})$, respectively.

We hypothesize that the abrupt increase in ResSST $_{\mathrm{SIO}}$, and implicitly SST $_{\mathrm{SIO}}$, in 1988 was due in part to enhancement of rip current transport of relatively warm surf-zone water at the present SIO pier. We assume that rip currents were associated with the old SIO pier. We propose that the $54 \%$ increase in area of pilings from the old $\left(13.3 \mathrm{~m}^{2}\right)$ to the present $\left(20.8 \mathrm{~m}^{2}\right)$ pier led to increased scouring and decreased wave energy and thus increased rip current transport. Comparable observations for the old SIO pier are not available and no longer possible. Hence, we are unable to rigorously test our hypothesis.
The only other shore station to show such a change in ResSST with both test types is the San Clemente pier (STARS, 1983; OLS-CUSUM, 1988; Figs. 3, 4b, 6-8). The SC pier was built in 1928 with wood pilings; it was extensively damaged during an El Niño in 1983 and repaired in 1985 with new and larger pilings. Although the SC time series is shorter and information limited, SST measured at both the SIO and SC piers may have been affected by similar structural enhancements and thus increased rip current transport.

Hare and Mantua (2000) analyzed time series of 100 physical (atmosphere, rivers, and ocean, including 

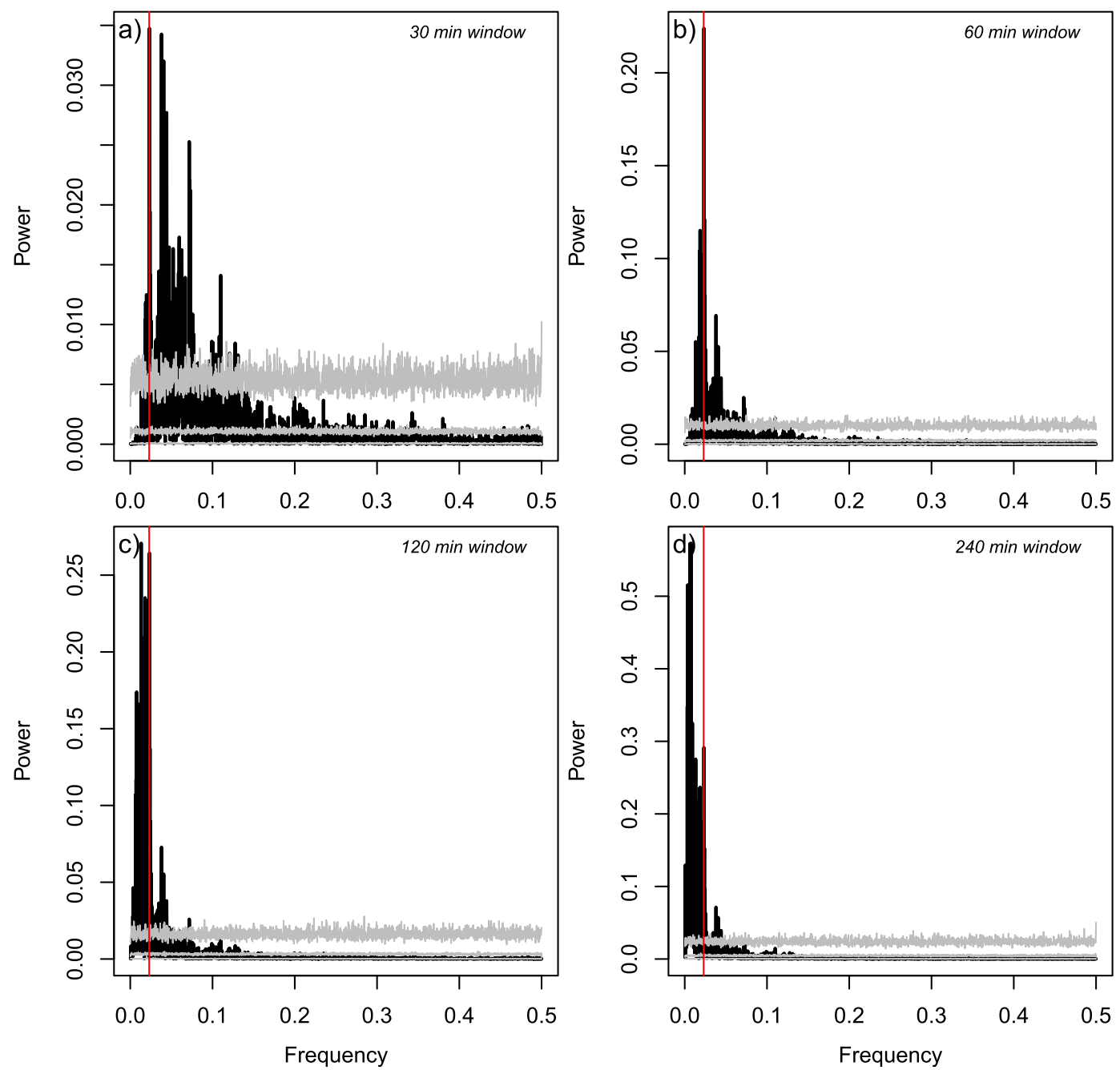

FIG. 10. (a)-(d) Power spectra of ResSST SIO using a double running-mean window of 30, 60, 120 and 240 min (Figs. 9e-h) relative to a distribution of Gaussian (white) noise. Mean and $95 \%$ confidence intervals are shown by horizontal gray lines, respectively. Most power is at periods longer than $40 \mathrm{~min}$ (vertical red line) but is removed when averaging window approaches as in (b) or is shorter than this period as in (a).

$\left.\mathrm{SST}_{\mathrm{SIO}}\right)$ and biological (plankton, nekton, and birds) variables together and in groups. In addition to a major change in 1977, an abrupt change in 1989 was observed in a number of cases, more for biological than physical variables, with $\mathrm{SST}_{\mathrm{SIO}}$ showing a relatively small increase (ibidem). Breaker (2007) and Breaker and Flora (2009) analyzed time series of SST for the SIO pier, PG, and Koko Head (KH), Hawaii. Brief decreases in SST in 1989 were observed at all three locations using CUSUM. A newer test, the method of expanding means, was used to assess long-term change associated with observed shifts and showed no response at SIO and $\sim 0.4^{\circ} \mathrm{C}$ decrease at KH. Rebstock (2002) analyzed copepod (zooplankton) abundance for 1951-99 in the CalCOFI region. Abrupt changes for some taxa, including late developmental stages of Calanus pacificus, occurred in 1989 but were neither consistent among taxa nor longlived. McGowan et al. (1998) showed SST to vary coherently and simultaneously on the annual time scale along the U.S. West Coast. Our use of residuals from the regression of annual-mean SST on the PDO and PC1 of the West Coast SST time series accounts for large-scale variation in SST. Thus, while such change occurred in the North Pacific in 1977 and the late 1980s, it does not explain the discontinuity in ResSST $\mathrm{SIO}_{\mathrm{S}}$ in 1988.

\section{Conclusions}

We show a positive discontinuity in ResSST $_{\text {SIO }}$ and, implicitly, SST $_{\text {SIO }}$ in 1988, after accounting for large-scale 
variation in SST represented by the PDO and PC1 of the other West Coast SST time series. This discontinuity is coincident with the change in measurement of $\mathrm{SST}_{\mathrm{SIO}}$ from the old to the present pier. We hypothesize this discontinuity is due in part to enhanced rip current transport of relatively warm surf-zone water to the location of measurement of SST $_{\text {SIO }}$. The discontinuity in 1988 (Fig. 1b) indicates the timing of the abrupt shift in the annual time series. The 1988 discontinuity $\left(+0.79^{\circ} \mathrm{C}\right.$; $\overline{\text { ResSST }_{\text {SIO,1989-2010 }}}-\overline{\text { ResSST }_{\text {SIO,1916-1987 }}}$; Fig. 1b) can be attributed to processes not accounted for by the PDO, including long-term warming $\left(+0.34^{\circ} \mathrm{C}\right.$; $\overline{\text { ERSST.v3b } \mathrm{b}_{1989-2010}}-\overline{\text { ERSST.v3b }}$ - $\left._{1916-1987}\right)$ and artifact $\left(+0.45^{\circ} \mathrm{C}\right)$ due to both rapid (1988 pier change) and gradual (e.g., time of day of $\mathrm{SST}_{\mathrm{SIO}}$ measurement) processes. It is incumbent on users of the $\mathrm{SST}_{\text {SIO }}$ time series to consider the sources of variability in $\mathrm{SST}_{\mathrm{SIO}}$ in each specific use. The long-term (1916 to present) trend of $\mathrm{SST}_{\mathrm{SIO}}$ without adjustment for artifact is $+1.1^{\circ} \mathrm{C}$ century ${ }^{-1}(p<0.001$; Mann-Kendall correlation $+0.299 ; p<0.001 ; n=93)$. If the $\operatorname{artifact}\left(+0.45^{\circ} \mathrm{C}\right)$ is subtracted from SIO $_{\text {SST }}$ from 1988 onward, the longterm trend is $+0.6^{\circ} \mathrm{C}_{\text {century }}{ }^{-1}(p=0.007$; MannKendall correlation $+0.190 ; p=0.007 ; n=93)$. While the unadjusted trend has been cited as evidence of faster increase of California coastal than global SST (Kadir et al. 2013), the adjusted trend is consistent with the twentieth-century trend in global SST $(+0.7 \pm$ $0.2^{\circ} \mathrm{C}$ century $^{-1}$; Smith et al. 2008).

This artifact may also have contributed to the more variable relationship between $\mathrm{SST}_{\text {SIO }}$ and recruitment of the Pacific sardine (Sardinops sagax) in recent decades (McClatchie et al. 2010; Sugihara et al. 2012; Lindegren and Checkley 2013), with implications for sardine management. $\mathrm{SST}_{\mathrm{SIO}}$ explained significant variability in the relationship between biomass and recruitment for the Pacific sardine based on data for 193563 and 1986-90 (Jacobson and MacCall 1995). This led to the use of the 3-yr running mean of annual-mean SST $_{\text {SIO }}$ in the fishery harvest guideline that determines the fraction ( $F$; percent) of available sardine biomass allocated for capture (e.g., Hill et al. 2011). Had SST SIO been adjusted for the artifact after 1988, $F$ would have decreased in cool years. For example, in 2001, the 3-yr running mean of $\mathrm{SST}_{\mathrm{SIO}}$ was $17.2^{\circ} \mathrm{C}$. An adjustment of $\mathrm{SST}_{\text {SIO }}$ by $-0.45^{\circ} \mathrm{C}$ would have decreased $F$ from $15 \%$ to $\sim 6 \%$, the sardine quota by $\sim 2 / 3$, and the ex-vessel landing revenues of the fishery by $\sim \$ 6$ million. A temperature index from the California Cooperative Oceanic Fisheries Investigations (CalCOFI) explains more variability than $\mathrm{SST}_{\text {SIO }}$ in the relationship between sardine biomass and recruitment (Lindegren and Checkley 2013). In March 2014, the Pacific Fishery Management
Council decided to use the CalCOFI temperature index rather than $\mathrm{SST}_{\mathrm{SIO}}$ in the sardine harvest guideline (Pacific Fishery Management Council 2014).

Time series of measurements from the SIO pier, including SST, are of increasing value, particularly in the context of climate change. Our intent in this paper has been to further increase the value of the SST $_{\text {SIO }}$ time series through an enhanced understanding of its properties. We strongly advocate it be continued.

Finally, three points merit mention. First, this study reemphasizes the need for the careful maintenance of environmental time series. What may appear to be small changes in protocol can have significant consequences for measurements. Any change in protocol should be critically assessed. Second, the interpretation of time series of environmental data must take into account any changes in protocol and their effects. Third, many coastal time series are from regular measurements made from piers. Such measurements may be affected by rip currents and hence changes in pier structure and wave power (e.g., Bromirski et al. 2013).

Acknowledgments. We thank Reinhard Flick, Melissa Carter, and Eric Terrill for access to data. We thank Mark Morales for help in field measurements. Melissa Carter, Dan Cayan, Falk Fedderson, Reinhard Flick, Robert Guza, Eddie Kisfaludy, and John McGowan provided valuable comments on the study. Mario Aguilera, three anonymous reviewers, and the editor provided constructive comments on the manuscript. ML was supported by a Scripps Institution of Oceanography (SIO) Postdoctoral Fellowship, with funds from SIO and NSF Grant OCE-0928425 to DMC.

\section{REFERENCES}

Akaike, H., 1974: New look at statistical-model identification. IEEE Trans. Autom. Control, 19, 716-723, doi:10.1109/tac.1974.1100705.

Breaker, L. C., 2007: A closer look at regime shifts based on coastal observations along the eastern boundary of the North Pacific. Cont. Shelf Res., 27, 2250-2277, doi:10.1016/j.csr.2007.05.018. — 1989 regime shifts in sea-surface temperature off Southern California and Hawai'i. Pac. Sci., 63, 39-60, doi:10.2984/ 1534-6188(2009)63[39:EOARSI]2.0.CO;2.

Bromirski, P. D., D. R. Cayan, J. Helly, and P. Wittmann, 2013: Wave power variability and trends across the North Pacific. J. Geophys. Res. Oceans, 118, 6329-6348, doi:10.1002/2013JC009189.

Brown, R. L., J. Durbin, and J. M. Evans, 1975: Techniques for testing the constancy of regression relationships over time. J. Roy. Stat. Soc., 37B, 149-163.

Chang, G., and M. S. Twardowski, 2011: Effects of physical forcing and particle characteristics on underwater imaging performance. J. Geophys. Res., 116, $\mathrm{C} 00 \mathrm{H} 03$, doi:10.1029/ 2011JC007098. 
Dalrymple, R. A., J. H. MacMahan, A. Reniers, and V. Nelko, 2011: Rip currents. Annu. Rev. Fluid Mech., 43, 551-581, doi:10.1146/annurev-fluid-122109-160733.

Dayton, P. K., M. J. Tegner, P. B. Edwards, and K. L. Riser, 1999: Temporal and spatial scales of kelp demography: The role of oceanographic climate. Ecol. Monogr., 69, 219-250, doi:10.1890/0012-9615(1999)069[0219:TASSOK]2.0.CO;2.

Deyle, E. R., and Coauthors, 2013: Predicting climate effects on Pacific sardine. Proc. Natl. Acad. Sci. USA, 110, 6430-6435, doi:10.1073/pnas.1215506110.

Farahani, R. J., R. A. Dalrymple, A. Herault, and G. Bilotta, 2014: Three-dimensional SPH modeling of a bar/rip channel system. J. Waterw. Port Coastal Ocean Eng., 140, 82-99, doi:10.1061/ (ASCE)WW.1943-5460.0000214.

Gargett, A. E., 1997: The optimal stability 'window': A mechanism underlying decadal fluctuations in North Pacific salmon stocks. Fish. Oceanogr., 6, 109-117, doi:10.1046 j.1365-2419.1997.00033.x.

Haller, M. C., R. A. Dalrymple, and I. A. Svendesen, 2002: Experimental study of nearshore dynamics on a barred beach with rip channels. J. Geophys. Res., 107 (C6), doi:10.1029/ 2001JC000955.

Hare, S. R., and N. J. Mantua, 2000: Empirical evidence for North Pacific regime shifts in 1977 and 1989. Prog. Oceanogr., 47, 103-145, doi:10.1016/S0079-6611(00)00033-1.

Hatch, M. B. A., 2012: The schlerochronology of Donax gouldii and Chione undatella: Environmental archives of the past and present Southern California Bight. Ph.D. dissertation, Scripps Institution of Oceanography, $128 \mathrm{pp}$.

- S. A. Schellenberg, and M. L. Carter, 2013: Ba/Ca variations in the modern intertidal bean clam Donax gouldii: An upwelling proxy? Palaeogeogr. Palaeoclimatol. Palaeoecol., 373, 98-107, doi:10.1016/j.palaeo.2012.03.006.

Hill, K. T., P. R. Crone, N. C. H. Lo, B. J. Macewicz, E. D. Dorval, J. D. McDaniel, and Y. Gu, 2011: Assessment of the Pacific sardine resource in 2011 for U.S. management in 2012. NOAA National Marine Fisheries Service, Southwest Fisheries Science Center Rep., 6 pp. [Available online at http://www.pcouncil. org/wp-content/uploads/F2b_ATT1_SARDINE_EXSUM_ NOV2011BB.pdf.]

Hobday, A. J., and M. J. Tegner, 2002: The warm and the cold: Influence of temperature and fishing on local population dynamics of red abalone. CalCOFI Rep., 43, 74-96. [Available online at www.calcofi.org/publications/calcofireports/v43/ Vol_43_Hobday___Tegner.pdf.]

Hsieh, C. H., S. M. Glaser, A. J. Lucas, and G. Sugihara, 2005: Distinguishing random environmental fluctuations from ecological catastrophes for the North Pacific Ocean. Nature, 435, 336-340, doi:10.1038/nature03553.

Jacobson, L., and A. MacCall, 1995: Stock-recruitment models for Pacific sardine (Sardinops sagax). Can. J. Fish. Aquat. Sci., 52, 566-577, doi:10.1139/f95-057.

_, and S. McClatchie, 2013: Comment on temperaturedependent stock-recruit modeling for Pacific sardine (Sardinops sagax) in Jacobson and MacCall (1995), McClatchie et al. (2010), and Lindegren and Checkley (2013). Can. J. Fish. Aquat. Sci., 70, 1566-1569, doi:10.1139/cjfas-2013-0128.

Jirka, G. H., K. D. Stolzenbach, and E. E. Adams, 1981: Buoyant surface jets. J. Hydraul. Div., 107, 1467-1487.

Kadir, T., L. Mazur, C. Milanes, and K. Randles, Eds., 2013: Indicators of climate change in California. Office of Environmental Health Hazard Assessment, California Environmental Protection Agency, 228 pp. [Available online at www.oehha.
ca.gov/multimedia/epic/pdf/ClimateChangeIndicatorsReport2013. pdf.]

Kim, H.-J., A. J. Miller, J. McGowan, and M. L. Carter, 2009: Coastal phytoplankton blooms in the Southern California Bight. Prog. Oceanogr., 82, 137-147, doi:10.1016/ j.pocean.2009.05.002.

Lavaniegos, B. E., and M. D. Ohman, 2003: Long-term changes in pelagic tunicates of the California Current. Deep-Sea Res. II, 50, 2473-2498, doi:10.1016/S0967-0645(03)00132-2.

Lindegren, M., and D. M. Checkley Jr., 2013: Temperature dependence of Pacific sardine (Sardinops sagax) recruitment in the California Current ecosystem revisited and revised. Can. J. Fish. Aquat. Sci., 70, 245-252, doi:10.1139/ cjfas-2012-0211.

, D. M. Checkley, T. Rouyer, A. D. MacCall, and N. C. Stenseth, 2013: Climate, fishing, and fluctuations of sardine and anchovy in the California Current. Proc. Natl. Acad. Sci. USA, 110, 13 672-13677, doi:10.1073/pnas.1305733110.

Mackas, D. L., and G. Beaugrand, 2010: Comparisons of zooplankton time series. J. Mar. Syst., 79, 286-304, doi:10.1016/ j.jmarsys.2008.11.030.

MacMahan, J. H., E. B. Thornton, and A. Reniers, 2006: Rip current review. Coastal Eng., 53, 191-208, doi:10.1016/ j.coastaleng.2005.10.009.

Mantua, N., S. Hare, Y. Zhang, J. Wallace, and R. Francis, 1997: A Pacific interdecadal climate oscillation with impacts on salmon production. Bull. Amer. Meteor. Soc., 78, 1069-1079, doi:10.1175/1520-0477(1997)078<1069:APICOW>2.0.CO;2.

McClatchie, S., R. Goericke, G. Auad, and K. Hill, 2010: Reassessment of the stock-recruit and temperature-recruit relationships for Pacific sardine (Sardinops sagax). Can. J. Fish. Aquat. Sci., 67, 1782-1790, doi:10.1139/f10-101.

McGowan, J. A., D. R. Cayan, and L. M. Dorman, 1998: Climateocean variability and ecosystem response in the northeast Pacific. Science, 281, 210-217, doi:10.1126/science.281.5374.210.

Miller, E. F., and J. A. McGowan, 2013: Faunal shift in Southern California's coastal fishes: A new assemblage and trophic structure takes hold. Estuarine Coastal Shelf Sci., 127, 29-36, doi:10.1016/j.ecss.2013.04.014.

Pacific Fishery Management Council, 2014: Decision summary document Pacific fishery management council meeting March 8-13, 2014. Pacific Fishery Management Council Rep., 6 pp. [Available online at www.pcouncil.org/wp-content/uploads/ 0314decisions.pdf.]

Parnell, P. E., E. F. Miller, C. E. Lennert-Cody, P. K. Dayton, M. L. Carter, and T. D. Stebbins, 2010: The response of giant kelp (Macrocystis pyrifera) in Southern California to lowfrequency climate forcing. Limnol. Oceanogr., 55, 2686-2702.

Ploberger, W., and W. Krämer, 1992: The CUSUM test with OLS residuals. Econometrica, 60, 271-285, doi:10.2307/2951597.

Prytherch, J., J. T. Farrar, and R. A. Weller, 2013: Moored surface buoy observations of the diurnal warm layer. J. Geophys. Res. Oceans, 118, 4553-4569, doi:10.1002/jgrc. 20360.

Rebstock, G. A., 2002: Climatic regime shifts and decadal-scale variability in calanoid copepod populations off southern California. Global Change Biol., 8, 71-89, doi:10.1046/ j.1365-2486.2002.00456.x.

Rodionov, S. N., 2004: A sequential algorithm for testing climate regime shifts. Geophys. Res. Lett., 31, L09204, doi:10.1029/ 2004GL019448.

Saeedi, M., A. A. Farahani, O. Abessi, and T. Bleninger, 2012: Laboratory studies defining flow regimes for negatively 
buoyant surface discharges into crossflow. Environ. Fluid Mech., 12, 439-449, doi:10.1007/s10652-012-9245-4.

Schwing, F. B., and R. Mendelssohn, 1997: Increased coastal upwelling in the California Current System. J. Geophys. Res., 102, 3421-3438, doi:10.1029/96JC03591.

Smith, J. A., and J. G. Largier, 1995: Observations of nearshore circulation: Rip currents. J. Geophys. Res., 100,10 967-10 975, doi:10.1029/95JC00751.

Smith, T. M., R. W. Reynolds, T. C. Peterson, and J. Lawrimore, 2008: Improvements to NOAA's historical merged landocean surface temperature analysis (1880-2006). J. Climate, 21, 2283-2296, doi:10.1175/2007JCLI2100.1.

Stockdon, H. F., R. A. Holman, P. A. Howd, and A. H. Sallenger, 2006: Empirical parameterization of setup, swash, and runup. Coastal Eng., 53, 573-588, doi:10.1016/j.coastaleng.2005.12.005.
Sugihara, G., R. May, H. Ye, C. H. Hsieh, E. Deyle, M. Fogarty, and S. Munch, 2012: Detecting causality in complex ecosystems. Science, 338, 496-500, doi:10.1126/science.1227079.

Tegner, M. J., P. K. Dayton, P. B. Edwards, and K. L. Riser, 1996: Is there evidence for long-term climatic change in Southern California kelp forests? CalCOFI Rep., 37, 111-126. [Available online at http://www.calcofi.org/publications/ calcofireports/v37/Vol_37_Tegner_etal.pdf.]

Twardowski, M., and Coauthors, 2012: The optical volume scattering function in a surf zone inverted to derive sediment and bubble particle subpopulations. J. Geophys. Res., 117, C00H17, doi:10.1029/2011JC007347.

Webster, P. J., C. A. Clayson, and J. A. Curry, 1996: Clouds, radiation, and the diurnal cycle of sea surface temperature in the tropical western Pacific. J. Climate, 9, 1712-1730, doi:10.1175/ 1520-0442(1996)009<1712:CRATDC >2.0.CO;2. 